\title{
O processo migratório em Santa Catarina: evidências a partir da microrregião de Joaçaba
}

Franciele Lagni Henriques*

Lauro Francisco Mattei**

\section{Resumo}

A mudança de domicílio para outra região, estado ou país é algo que vem ocorrendo a muito tempo e que faz parte da realidade humana. Todavia, sempre é importante analisar as condições específicas em que ocorrem esses processos migratórios e os fatores que os influenciam. Este estudo aborda a migração na microrregião de Joaçaba no período entre 2000 e 2010 com o objetivo de compreender as características gerais desse movimento migratório de caráter microrregional. Após fazer um breve debate sobre as distintas interpretações teóricas, analisou-se um conjunto de informações para cada uma das três secretarias de desenvolvimento regional que fazem parte dessa microrregião, calculando-se o saldo migratório e as próprias taxas de migração. A principal conclusão do trabalho é que a microrregião de Joaçaba continua sendo um espaço com saldos migratórios negativos, o que significa dizer que é uma região geográfica que libera pessoas para outros locais do estado de Santa Catarina e do próprio país.

Palavras-chave: Santa Catarina, Migrações, Microrregião de Joaçaba.

*Graduada em Economia pela UFSC (franlanhi@ hotmail.com).

** Professor Doutor do PPGG em Administração e Departamento de Economia e Relações Internacionais - CSE/UFSC (1.mattei@ufsc.br).

Geosul, Florianópolis, v. 28, n. 56, p 65-88, jul./dez. 2013 
MATTEI, L.F. \& HENRIQUES, F.L. O processo migratório em Santa ...

The migratory process in the Santa Catarina State: some evidences from Joaçaba micro-region

\section{Abstract}

The change in the residence from one region to another is a fact that is happened a long time, and is a part of the human society. However, is important to analyze the specifics conditions that to carry out these migration process, and the factors that are involved. This article discuss the phenomenon in the Joaçaba micro-region between 2000 and 2010 with the objectives to understand the general characteristics of this process. After made a theoretical distinction of this issue, we analyzed many information in each Regional State Organisms that take a place in the Joaçaba microregion, specially the migration perceptual and the balance of this migratory movement. The main conclusion of the paper is that Joaçaba micro-region still has a negative population balance. This mean that this is a geographic place that lost population for another places of Santa Catarina State.

Key words: Santa Catarina State, Migration, Joaçaba microregion.

\section{Introdução}

A Microrregião de Joaçaba pertence à mesorregião Oeste Catarinense e seu processo de colonização ocorreu entre as décadas de 1910 e 1960. A grande maioria dos colonizadores era descendente de italianos que migrou da serra gaúcha, especialmente das cidades de Caxias do Sul e Bento Gonçalves (RS), os quais foram atraídos pelas propagandas governamentais que enfatizavam a possibilidade de recriação de suas práticas culturais e econômicas (SANTOS, 1998).

Em razão da abundância de terras férteis e com preços acessíveis, clima favorável, proximidade com a estrada-de-ferro e a quantidade de mão-de-obra que migrou para essa região, o 
MATTEI, L.F. \& HENRIQUES, F.L. O processo migratório em Santa ...

comércio local cresceu rapidamente. Inicialmente a economia foi comandada pela agricultura familiar voltada ao mercado interno, sendo que atualmente em toda a região Oeste ocorre o predomínio das atividades econômicas ligadas direta ou indiretamente às agroindústrias.

Também conhecida como Vale do Rio do Peixe, a microrregião de Joaçaba é composta por 27 municípios dentro os quais, 11 são banhados pelo Rio do Peixe. Nesta microrregião estão localizadas três Secretarias de Desenvolvimento Regional (SDR): a de Caçador, de Joaçaba e de Videira. A secretaria de desenvolvimento regional de Joaçaba é composta pelos municípios de Água Doce, Capinzal, Catanduvas, Erval Velho, Herval d' Oeste, Jaborá, Ibicaré, Joaçaba, Lacerdópolis, Luzerna, Ouro, Treze Tilhas e Vargem Bonita, conforme Figura 1. A SDR de Caçador contêm os municípios de Caçador, Calmon, Lebon Régis, Macieira, Matos Costa, Rio das Antas e Timbó Grande (Figura 2); e a SDR de Videira abrange os municípios de Arroio Trinta, Fraiburgo, Iomerê, Pinheiro Preto, Salto Veloso, Tangará e Videira, conforme Figura 3. (SDR, 2010)

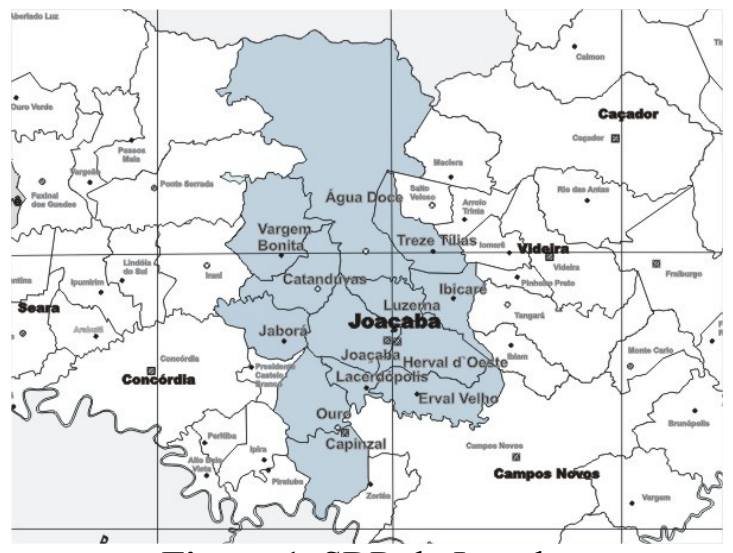

Figura 1: SDR de Joaçaba

Fonte: Governo de Santa Catarina, 2011. 
MATTEI, L.F. \& HENRIQUES, F.L. O processo migratório em Santa ...

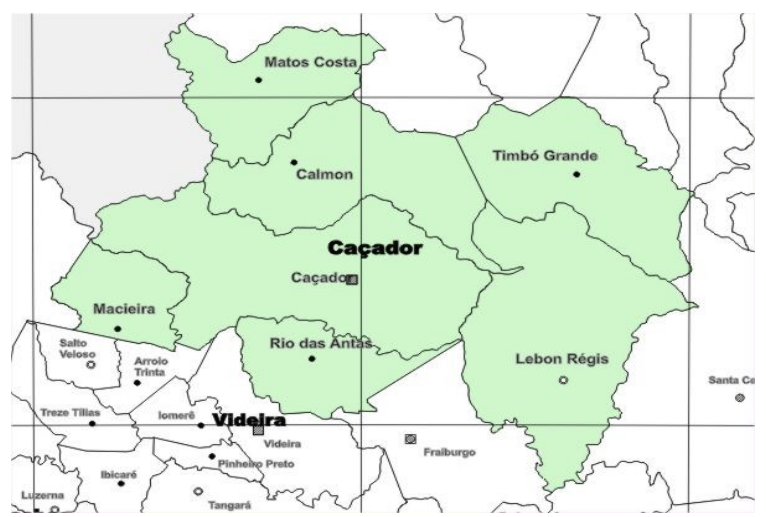

Figura 2: SDR de Caçador

Fonte: Governo de Santa Catarina, 2011.

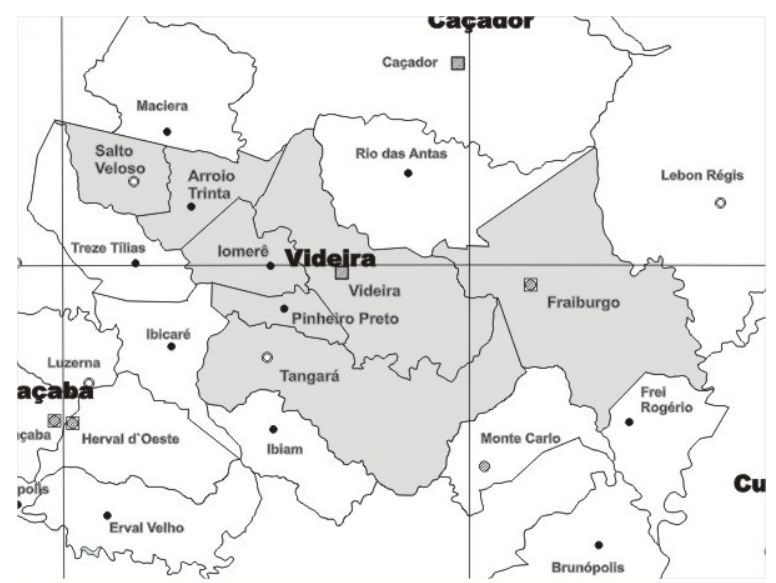

Figura 3: SDR de Videira

Fonte: Governo de Santa Catarina, 2011.

Como visto anteriormente, no início do século XX o processo de migração dessa região caracterizou-se por um fluxo migratório rural-rural que influenciou na dinâmica economia local 
MATTEI, L.F. \& HENRIQUES, F.L. O processo migratório em Santa ...

e em todas as áreas do macro ambiente. Pode-se perceber que os movimentos migratórios estão presentes desde tempos antigos. Porém, com o passar do tempo, as características dos fluxos migratórios foram se transformando, sendo que hoje o principal fluxo é no sentido rural-urbano e urbano-urbano.

Migrar faz parte da vida humana, mas toda migração implica em um processo de mudanças. Esses fluxos influenciam socioeconomicamente e geograficamente os espaços envolvidos e estão diretamente interligadas no desenvolvimento de cada região. Por isso, é importante analisar as condições nos quais ocorrem esses processos migratórios e os fatores que estão provocando esses deslocamentos populacionais.

Neste sentido, o artigo tem como objetivo principal analisar as características do movimento migratório da microrregião de Joaçaba no período entre 2000 a 2010. Para tanto, além desta breve introdução, ele contém mais quatro seções. Na primeira delas é feita uma breve discussão sobre os argumentos teóricos utilizados para explicar os processos migratórios. A segunda seção discute o processo de colonização da microrregião de Joaçaba e suas condições socioeconômicas. Já a terceira seção apresenta os dados populacionais, o saldo migratório no período entre 2000 e 2010 e as principais tendências na microrregião, utilizando dados para cada uma das três Secretarias de Desenvolvimento Regional. Finalmente, a quarta seção apresenta as considerações finais do trabalho, destacando que essa microrregião analisada continua sendo um local de imigração da população.

\section{Breves notas sobre interpretações das migrações}

Migração é um fenômeno estudado de uma forma muito heterogênea, sendo diversos os enfoques que se tem dado ao processo de deslocamento populacional, especialmente nos campos da Antropologia, Demografia, Economia, Sociologia, História e Geografia. As teorias produzidas sobre migração sofreram mudanças, em sua maioria, influenciadas pelo mundo industrial e 
MATTEI, L.F. \& HENRIQUES, F.L. O processo migratório em Santa ...

pelo desenvolvimento econômico. Na Economia, particularmente, existe duas correntes teóricas que interpretam e analisam $\mathrm{o}$ problema: a teoria neoclássica e a teoria estruturalista.

No primeiro caso destacam-se os estudos de Ravenstein (1980) que em sua obra "As Leis da Migração" analisou os movimentos migratórios com base em dados estatísticos do Censo Populacional do Reino Unido de 1881. Tendo a sensação de que a migração parecia ocorrer sem qualquer lei definida, ele formulou as "leis da migração" visando demonstrar a influência dos fatores econômicos sobre a decisão de migrar.

Em sua obra são citados diversos fatores que ocasionam uma decisão de migração, como por exemplo, o clima, o solo, vegetação, recursos naturais, nível de desenvolvimento econômico, educação, religião, tecnologia, urbanização e emprego. Além disso, o autor classifica os fluxos migratórios em migrantes locais de curtas e médias distâncias e migrantes temporários - caracterizados pela população "flutuante".

$\mathrm{O}$ autor identificou que os motivos econômicos eram as principais causas que levavam ao deslocamento das pessoas, principalmente pelas diferenças econômicas existentes, pelo desejo de melhorar de vida e pelo êxodo rural. E com base nos comentários de Everett Lee, identificou a influência que os novos recursos técnicos (desenvolvimento dos meios de locomoção, indústria e comércio) exerciam sobre as pessoas.

Para Ravenstein (1980, p.26) as grandes cidades proporcionam facilidades tão extraordinárias à divisão e à combinação do trabalho, ao exercício de todas as artes e à prática de todas as profissões que, a cada ano, um número maior de pessoas nelas possa habitar. Assim, o autor afirmou que a procura de mão-de-obra nos centros industriais e comerciais foi, sem dúvida, a causa primeira das correntes migratórias. Essa tese está na base da fundamentação neoclássica, que qualifica o fenômeno da migração como sendo de vontades espontâneas dos indivíduos a se deslocarem, especialmente influenciadas pelas possibilidades de se obter maiores vantagens econômicas. 
MATTEI, L.F. \& HENRIQUES, F.L. O processo migratório em Santa ...

Segundo Salim (1992), para a visão neoclássica os estudos sobre migração pressupõem o cálculo racional e a livre decisão dos indivíduos - ou seja, a mesma lógica locacional das firmas, em que o indivíduo vai agir racionalmente calculando os custos $\mathrm{e}$ benefícios que terá para desenvolver a curva de utilidade. No centro do processo migratório há uma decisão de um indivíduo entre a permanência ou a migração, tendo em vista a posse de informações sobre as características das possíveis regiões de mudança, bem como da situação individual e coletiva.

Em síntese, para a teoria neoclássica os fatores de migração no local de origem e de destino podem ser positivos, negativos ou nulos, sendo que o saldo desses fatores somado aos obstáculos intervenientes e fatores pessoais é quem determina a decisão de migrar. Decorre daí que a explicação de migração afirma que são os fatores positivos e negativos que levaram as pessoas a migrarem das áreas consideradas repulsivas (Push) para áreas de atração (Pull).

Já a linha teórica estruturalista dá ênfase às relações sociais e mudanças estruturais como determinantes dos fluxos e não aos cálculos individuais. Autores desta corrente de pensamento dão outro tipo de tratamento aos processos migratórios, uma vez que consideram que os fluxos migratórios ocorrem em decorrência das novas necessidades e ditames que o desenvolvimento econômico passa a exigir.

No caso brasileiro, esta corrente contou com a grande contribuição do economista Paul Singer. Para este autor, a migração está historicamente condicionada aos processos de industrialização e do desenvolvimento econômico, uma vez que as migrações internas não parecem ser mais que um mero mecanismo de redistribuição espacial das atividades econômicas. Desta forma, Singer entende que o estudo das migrações deixa de ter sentido quando tratado como um movimento de indivíduos, pois as livres e espontâneas vontades dos indivíduos não são estáticas, sendo modificadas no tempo.

Há dois fatores, segundo esse autor, que atuando em conjunto provocam os deslocamentos populacionais. O primeiro é 
MATTEI, L.F. \& HENRIQUES, F.L. O processo migratório em Santa ...

o fator de expulsão (divididos em fatores de mudança e fatores de estagnação) e o segundo é o de atração. Os fatores de expulsão das regiões são ocasionados pelas transformações ocorridas na área de origem e problemas sociais postos pela nova realidade da sociedade, como os excedentes econômicos, as transformações no mundo do trabalho - decorrentes da industrialização e globalização - e o crescimento exorbitante das cidades. Os fatores de mudanças se referem à introdução de formas capitalistas com novas técnicas de produção, causando um aumento da produtividade local e, consequentemente, redução do nível de emprego, estimulando as pessoas a migrarem para outras áreas.

Já os fatores de estagnação estão associados à escassez de recursos, a qual gera a impossibilidade de se obter ganhos monetários apenas a partir da produtividade da terra. Com isso, conformam-se pressões populacionais sobre os meios de produção, particularmente na agricultura onde a disponibilidade de terras é limitada pelo monopólio dos grandes proprietários ou pela insuficiência física de áreas produtivas. Esses fatores acabam orientando então o movimento migratório em direção às regiões beneficiadas por fatores de atração.

Os fatores de atração determinam as áreas para as quais se direcionam os fluxos migratórios, sendo que para isso contribuem desde a oferta de serviços públicos em todas as esferas até a expansão da demanda por força de trabalho (considerada o fator mais importante, pois faz parte das expectativas de rendimento dos indivíduos). Porém, o autor adverte que neste movimento sempre existirão obstáculos com os quais o migrante irá se deparar, podendo levar a um processo de marginalização e de exclusão social.

Tendo em consideração essa discussão teórica, as próximas seções irão discutir o processo migratório em uma região específica do estado de Santa Catarina. Para tanto, inicialmente caracteriza-se a mesma para, posteriormente, buscar compreender os fatores envolvidos naquele espaço geográfico que interferem no processo migratório. 
MATTEI, L.F. \& HENRIQUES, F.L. O processo migratório em Santa ...

\section{Principais características históricas e socioeconômicas da microrregião de Joaçaba (SC)}

A região do Oeste e Meio Oeste, palco de diversos conflitos sociais, foi a última área a ser colonizada no estado catarinense. A partir de 1917, quando pacificada, conheceu forte colonização de imigrantes vindos do Rio Grande do Sul - sendo este processo colonizador dominado por descendentes dos imigrantes europeus. Estima-se que naquela época cerca de 300 mil pessoas se deslocaram do Rio Grande do Sul para Santa Catarina.

Em 1910 inaugurou-se a estrada de ferro São Paulo-Rio Grande, um ponto importante para a colonização do Vale do Rio do Peixe. Muitos trabalhadores que vieram para construção da ferrovia permaneceram na região, colaborando com o processo de colonização da mesma, sendo o primeiro povoado estabelecido em torno da estação ferroviária que se chamou "Colônia Bom Retiro" - local atualmente próximo a cidade de Joaçaba. Já em 1923 formaram-se os municípios de Capinzal, Piratuba e Concórdia (REGENSBURGER, 2006).

Juntando os imigrantes que chegaram nessa região, a pavimentação de estradas e as demarcações territoriais feitas pelas companhias de colonização - esse território destacou-se economicamente, principalmente pela exploração de madeira e erva mate e de pequenas atividades agropecuária - formando-se o sistema capitalista de produção local (GOULARTI FILHO, 2010).

$\mathrm{O}$ bom conhecimento das atividades agrícolas dos imigrantes, como a criação de animais (destacando os suínos e aves) e as atividades de subsistência, somado à disponibilidade de boas terras para a agricultura, explica o destaque de todo o Oeste e Meio Oeste como área fornecedora de alimentos e seu papel fundamental no setor primário da economia catarinense.

Nesta região a produção agropecuária ganhou destaque através do cultivo de produtos básicos como milho, arroz e feijão, além da criação de animais, principalmente de aves e suínos. Os minifúndios que foram estabelecidos se transformaram no fator 
MATTEI, L.F. \& HENRIQUES, F.L. O processo migratório em Santa ...

chave para a implantação e consolidação do sistema agroindustrial, principal polo da produção regional. Nessa época, destaca-se o surgimento dos frigoríficos da Perdigão em Videira e Ouro (1938), em Capinzal e Pagnoncelli (1942) e em Herval do Oeste (REGENSBURGER, 2006).

Especificamente em relação à região de Joaçaba, a circulação de riqueza proveniente da produção de trigo também contribuiu para o surgimento de novas atividades, como o de máquinas industriais e agrícolas. Outro setor que se desenvolveu e se destacou na região foi o metal-mecânico (REGENSBURGER, 2006). Segundo essa autora, a cidade de Joaçaba possuía, nos anos de 1960, um parque industrial desenvolvido nas áreas de motores, turbinas hidráulicas e máquinas e equipamentos agrícolas, além dos tradicionais moinhos de trigo e fábricas de móveis. Todavia, todas essas atividades sempre guardaram uma relação muito próxima com as atividades agropecuárias.

Este cenário sofreu profundas alterações a partir da década de 1980, quando a crise econômica geral do país também afetou a região. A partir de então esta passou a enfrentar problemas para manter a produção agrícola local; a indústria foi parcialmente reestruturada perdendo espaço na produção econômica regional; os avanços tecnológicos e a concorrência capitalista reduziram enormemente as oportunidades de trabalho; houve perda de renda dos produtores rurais, fazendo com que muitos deles tivessem dificuldades para continuar as atividades produtivas; etc. Todos estes fatores aparecem como elementos essenciais para se entender o processo migratório em curso que será discutido na seção seguinte.

De maneira geral, apresentamos a seguir algumas informações específicas sobre as tendências demográficas recentes da microrregião de Joaçaba. Ressalta-se que essas informações foram analisadas tomando-se como referência as três Secretarias de Desenvolvimento Regional (SDRs). Agregadamente, segundo IBGE 2010, a população da microrregião de Joaçaba é composta por 331.681 habitantes, o que equivale a $5,3 \%$ da população do estado de Santa Catarina. Essa microrregião apresentou um 
MATTEI, L.F. \& HENRIQUES, F.L. O processo migratório em Santa ...

aumento na taxa de crescimento populacional desde o censo demográfico realizado em 2000 , porém essa taxa foi menor que a taxa agregada do estado de SC (7,4\% versus $16,65 \%)$.

A tabela 1 apresenta os dados das três SDR's integrantes da microrregião de Joaçaba. Inicialmente nota-se que a SDR de Videira apresentou a maior taxa de crescimento $(8,4 \%)$ no período entre 2000 e 2010. Já as demais apresentaram uma taxa de $8 \%$ (SDR de Caçador) e 6,1\% (SDR de Joaçaba). Conforme o Censo de 2010 do IBGE, a população das SDR's de Joaçaba, Caçador e Videira é composta por 123.615; 103.962; e 104.104 habitantes, respectivamente.

O município de Caçador com 70.762 habitantes é o mais populoso da microrregião, seguido por Videira com 47.188 habitantes, Fraiburgo com 34.553 habitantes e Joaçaba com 27.020 habitantes. Esses quatro municípios respondem por $54 \%$ da população da microrregião.

Tabela 1: Distribuição espacial da população - microrregião de Joaçaba

\begin{tabular}{|c|c|c|c|c|}
\hline \multirow{4}{*}{ SDR's } & \multicolumn{4}{|c|}{ Número de habitantes - área rural e urbana (2000-2010) } \\
\hline & \multicolumn{2}{|c|}{2000} & \multicolumn{2}{|c|}{2010} \\
\hline & Rural & Urbano & Rural & Urbano \\
\hline & \multicolumn{2}{|c|}{ TOTAL } & \multicolumn{2}{|c|}{ TOTAL } \\
\hline \multirow{2}{*}{ Caçador } & 25.736 & 70.469 & 21.106 & 82.883 \\
\hline & \multicolumn{2}{|c|}{96.205} & \multicolumn{2}{|c|}{103.989} \\
\hline \multirow{2}{*}{ Joaçaba } & 34.691 & 81.720 & 26.900 & 96.715 \\
\hline & \multicolumn{2}{|c|}{116.411} & \multicolumn{2}{|c|}{123.615} \\
\hline \multirow{2}{*}{ Videira } & 21.575 & 74.398 & 17.567 & 86.537 \\
\hline & \multicolumn{2}{|c|}{95.973} & \multicolumn{2}{|c|}{104.104} \\
\hline
\end{tabular}

Fonte: Elaboração própria a partir dos dados do IBGE

Quanto à distribuição populacional segundo o gênero, o dados do IBGE de 2010 revelam que na microrregião as mulheres representam $50,25 \%$ da população e os homens 49,74\%. No âmbito das SDR's, observa-se que a SDR de Caçador é a única secretaria em que os homens detêm uma porcentagem maior $(50,07 \%)$ na população total. 
MATTEI, L.F. \& HENRIQUES, F.L. O processo migratório em Santa ...

Segundo dados do IPEADATA (2011), a população economicamente ativa da microrregião de Joaçaba no ano de 2000 representava $49,7 \%$ da população, sendo que deste percentual mais de $72 \%$ já se encontrava localizado em áreas urbanas, o que implicou em uma diminuição da população rural com conjunto da PEA microrregional.

Do ponto de vista da participação da estrutura econômica microrregional, nota-se que a mesma tem uma pequena contribuição no conjunto do estado, ou seja, a microrregião de Joaçaba representa menos de $6 \%$ do PIB estadual. Porém, internamente à microrregião, nota-se que a SDR de Joaçaba é responsável por quase $45 \%$ do total agregado.

O gráfico 1 apresenta a participação setorial no PIB microrregional no período entre 2002 e 2008. A evolução da participação dos setores econômicos no PIB da microrregião revela que o setor industrial e de serviços respondem pela maior participação no PIB desse período, sendo que nos dois primeiros anos o setor industrial detinha a maior participação no PIB, mas o setor de serviços passou a predominar a partir de 2006.

$\mathrm{O}$ setor agropecuário vem perdendo participação no PIB, sendo que no ano de 2008 representava apenas 11,09\% do PIB microrregional. Neste mesmo ano o setor industrial respondeu por $39 \%$, enquanto o setor de serviços contribuiu com $41,03 \%$. De alguma forma, isso revela que as principais atividades econômicas da microrregião (indústria e serviços) cresceram mais e suas participações se distanciaram muito da participação do setor agropecuário.

Em termos de indicadores sociais, verifica-se que as contradições encontradas nas demais regiões do estado também estão presentes na microrregião de Joaçaba, destacando-se que alguns municípios se situam dentre aqueles com os melhores indicadores sociais, enquanto outros figuram no grupo de localidades com sérios problemas nesta esfera. 
MATTEI, L.F. \& HENRIQUES, F.L. O processo migratório em Santa ...

Gráfico 1: Evolução do PIB - setores econômicos - microrregião de Joaçaba

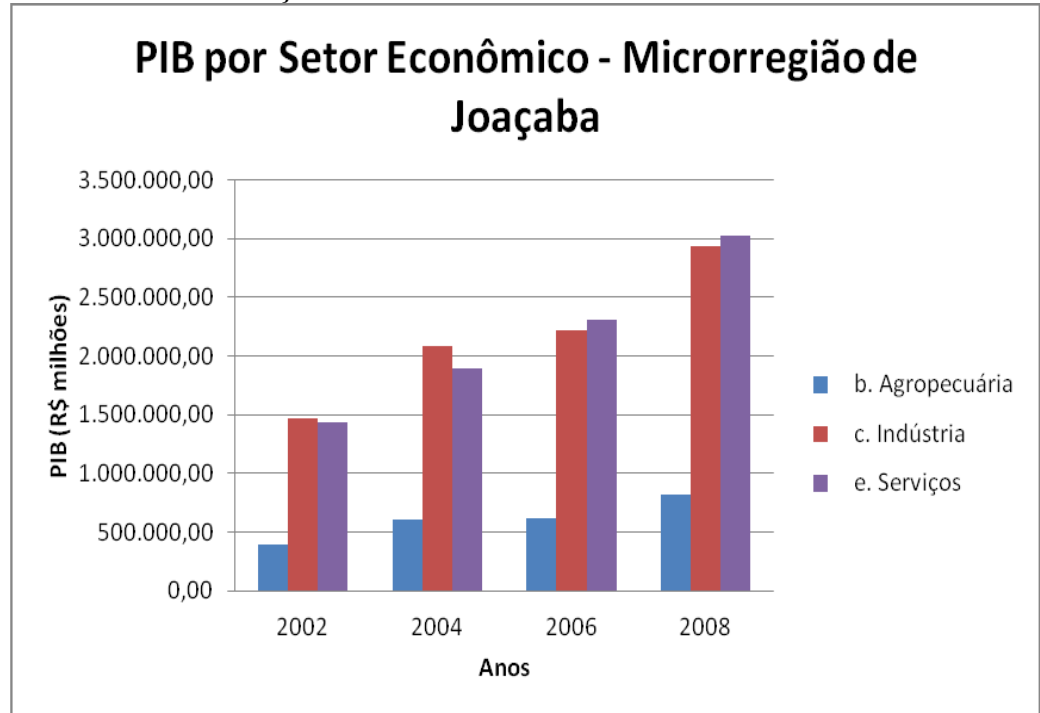

Fonte: Elaboração própria com base nos dados do IBGE e da Confederação Nacional dos Municípios

O IDH-M (Índice de Desenvolvimento HumanoMunicípios) revela, por exemplo, que a cidade de Joaçaba, com um índice de 0,816, se situa dentre os melhores municípios do Estado. Internamente à microrregião também se destacam positivamente os municípios de Luzerna, Lacerdópolis, Videira e Iomerê. Já os Municípios de Timbó Grande e Calmon apresentam os piores IDHM da microrregião, com 0,61 e 0,340, o que os coloca dentre os piores índices de desenvolvimento de Santa Catarina. Com isso, nota-se a existência de desequilíbrios sociais na microrregião, pois mesmo que a maioria das localidades apresente bons índices de IDH, alguns municípios não acompanham o mesmo desenvolvimento humano e se situam no grupo estadual com os piores desempenhos no ranking de indicadores. 
MATTEI, L.F. \& HENRIQUES, F.L. O processo migratório em Santa ...

\section{O processo migratório na microrregião de Joaçaba}

Como em todo o território estadual, os fluxos migratórios do Vale do Rio do Peixe vêm historicamente acompanhando o desenvolvimento econômico local. A partir dos anos de 1980 o espaço rural passa a perder progressivamente sua parcela de população para o meio urbano. A industrialização, a diversificação das atividades econômicas e as expectativas de maiores renda nas cidades, chamam a atenção da população rural - resultando em mudanças na mobilidade espacial.

O gráfico 2 ilustra melhor mostra o grau de urbanização ocorrido nesse intervalo de tempo, nas secretarias da microrregião e no estado de Santa Catarina. A microrregião como um todo apresentou um grau de urbanização em 2010 de 80,23\%, acompanhando a média estadual. Com isso, a microrregião de Joaçaba se situava no ano de $2010 \mathrm{em} 9^{\circ}$ lugar dentre todas as demais microrregiões do estado com maior grau de urbanização, processo este que é liderado pela microrregião da Grande Florianópolis onde esse grau atingiu $95,50 \%$ no último censo demográfico.

Os dados do Censo demográfico do IBGE de 2010 revelaram também que dos 20 municípios catarinenses com maior êxodo rural, quatro deles se localizam na microrregião de Joaçaba (Catanduvas, Calmon, Piratuba e Capinzal).

Para facilitar as análises da migração na microrregião selecionada, as informações foram desagregadas por SDRs. De um modo geral, pode-se dizer que a trajetória populacional nos âmbito das secretarias apresentou uma tendência quase que homogênea, ou seja, verificou-se que em todas as cidades com o maior contingente populacional ocorreram taxas mais elevadas de crescimento dentre os municípios. Este fato também se repetiu em alguns municípios com população entre de 3.000 a 8.000 habitantes, como foi o caso de Treze Tílias, Catanduvas, Pinheiro Preto e Timbó Grande. 
MATTEI, L.F. \& HENRIQUES, F.L. O processo migratório em Santa ...

Gráfico 2: Grau de Urbanização na Microrregião de Joaçaba e em Santa Catarina entre 2000 e 2010

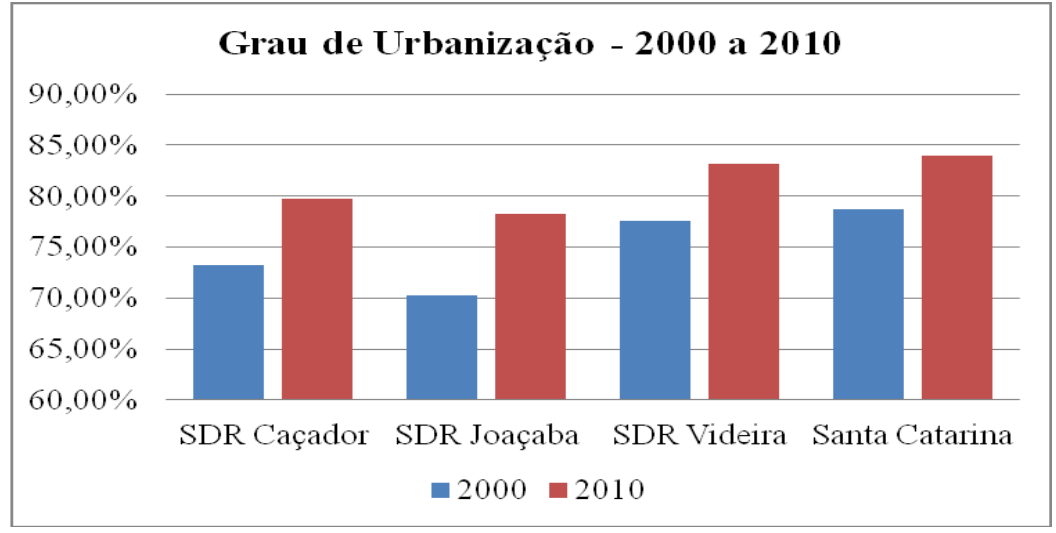

Fonte: Elaboração própria com base nos dados dos Censos Demográficos Populacionais - IBGE

A tabela 2 apresenta o saldo migratório e a taxa líquida de migração da SDR de Joaçaba no período entre 2000 e 2010. Inicialmente, observa-se que a região apresenta um saldo negativo, ou seja, saíram mais indivíduos do que permaneceram no local, caracterizando-se assim como uma área de expulsão populacional. Apenas os municípios de Catanduvas, Joaçaba e Treze Tílias apresentaram saldos migratórios positivos, destacando-se o caso de Treze Tília com o maior saldo migratório de toda a microrregião de Joaçaba. Já Capinzal (pior saldo migratório) e Vargem Bonita foram os municípios que apresentaram as maiores taxas negativas de perda de população no último ano considerado. 
MATTEI, L.F. \& HENRIQUES, F.L. O processo migratório em Santa ...

Tabela 2: Saldo Migratório e Taxa Líquida de Migração referente à SDR de Joaçaba 2000 a 2010

\begin{tabular}{|c|c|c|c|c|}
\hline O MIG & ORIOET & MIC & & \\
\hline Municípios & $\begin{array}{c}\text { Saldo } \\
\text { População } \\
\text { 2000-2010 }\end{array}$ & $\begin{array}{c}\text { Mortalidade } \\
\text { (Nsc. vivos - } \\
\text { óbtos) }\end{array}$ & SM & TLM \% \\
\hline Água Doce & 118 & 714 & -596 & $-8,56$ \\
\hline Capinzal & 814 & 2.737 & -1.923 & $-9,26$ \\
\hline Catanduvas & 1.264 & 1.119 & 145 & 1,52 \\
\hline Erval Velho & 83 & 245 & -162 & $-3,72$ \\
\hline Herval d' Oeste & 1.195 & 1.996 & -801 & $-3,77$ \\
\hline Ibicaré & -214 & 129 & -343 & $-10,17$ \\
\hline Jaborá & -153 & 218 & -371 & $-9,18$ \\
\hline Joaçaba & 2.954 & 2.381 & 573 & 2,12 \\
\hline Lacerdópolis & 26 & 109 & -83 & $-3,77$ \\
\hline Luzerna & 28 & 192 & -164 & $-2,93$ \\
\hline Ouro & -47 & 546 & -593 & $-8,04$ \\
\hline Treze Tilhas & 1.501 & 500 & 1.001 & 15,79 \\
\hline Vargem Bonita & -365 & 673 & -1.038 & $-21,66$ \\
\hline TOTAL & 7.204 & 11.559 & -4.355 & $-3,52$ \\
\hline
\end{tabular}

Fonte: Elaboração própria segundo os dados dos Censos Demográficos IBGE e Estatística Vitais - DATASUS/MS

A tabela 3 apresenta o saldo migratório e a taxa líquida de migração da SDR de Videira no período entre 2000 e 2010. Inicialmente deve-se registrar que esta secretaria apresentou uma característica diferente, comparativamente à SDR de Joaçaba, uma vez que nem todos os municípios que tiveram crescimento populacional no período apresentaram saldos migratórios e taxas líquidas positivas de migração. Assim, o saldo migratório total revelou-se negativo, caracterizando a SDR de Videira como uma área de expulsão dentro da microrregião de Joaçaba. Neste caso, notou-se, ainda, que cidades pequenas e com menos de cinco mil habitantes (Salto Veloso, Iomerê e Pinheiro Preto) tiveram saldos migratórios positivos, enquanto Fraiburgo (segunda cidade com maior população na SDR) apresentou a maior perda de população da secretaria, com uma taxa líquida negativa da ordem de $8,20 \%$. 
MATTEI, L.F. \& HENRIQUES, F.L. O processo migratório em Santa ...

Tabela 3: Saldo Migratório e Taxa Líquida de Migração referente à SDR de Videira 2000 a 2010

\begin{tabular}{l|c|c|r|r}
\hline \multicolumn{1}{c}{ SALDO MIGRATÓRIO E TAXÁpios } & $\begin{array}{c}\text { Saldo } \\
\text { População } \\
\mathbf{2 0 0 0 - 2 0 1 0}\end{array}$ & $\begin{array}{c}\text { Mortalidade } \\
\text { (Nsc. Vivos } \\
\text { - óbtos) }\end{array}$ & SM & TLM \% \\
\hline Arroio Trinta & 12 & 161 & -149 & $-4,25$ \\
\hline Fraiburgo & 1.605 & 5.530 & -3.925 & $-11,36$ \\
\hline Iomerê & 186 & 117 & 69 & 2,52 \\
\hline Pinheiro Preto & 418 & 224 & 194 & 6,16 \\
\hline Salto Veloso & 391 & 293 & 98 & 2,28 \\
\hline Tangará & -80 & 631 & -711 & $-8,20$ \\
\hline Videira & 5.599 & 5.762 & -163 & $-0,35$ \\
\hline TOTAL & $\mathbf{8 . 1 3 1}$ & $\mathbf{1 2 . 7 1 8}$ & $\mathbf{- 4 . 5 8 7}$ & $\mathbf{- 4 , 4 1}$ \\
\hline
\end{tabular}

Fonte: Elaboração própria segundo os dados dos Censos Demográficos IBGE e Estatística Vitais - DATASUS/MS

A tabela 4 apresenta o saldo migratório e a taxa líquida de migração da SDR de Caçador no período entre 2000 e 2010. Inicialmente verifica-se que a secretaria de Caçador foi aquela que apresentou os piores saldos migratórios. Com isso, representou a maior área de expulsão da microrregião de Joaçaba, uma vez que nenhum dos municípios que compõem essa SDR apresentou saldos migratórios positivos. Além disso, registre-se que o índice negativo do saldo migratório total foi o maior dentre todas as SDR's da microrregião. Nesta parte do território também se localiza o município (Matos Costa) que apresentou a maior taxa migratória em relação à população da microrregião em 2010.

Ao se analisar a microrregião em seu conjunto e compará-la com a dinâmica estadual, pode-se concluir que a microrregião de Joaçaba continua sendo uma área de expulsão de população mesmo com o aumento de sua população de 2000 para 2010 - visto que apresentou saldos migratórios predominantemente negativos, apesar de que um pequeno número de municípios tenha apresentado saldos positivos. 
MATTEI, L.F. \& HENRIQUES, F.L. O processo migratório em Santa ...

Tabela 4: Saldo Migratório e Taxa Líquida de Migração referente à SDR de Caçador - 2000 a 2010

SALDO MIGRATORIO - SDR CAÇADOR

\begin{tabular}{l|c|c|c|c}
\hline Municípios & $\begin{array}{c}\text { Saldo } \\
\text { População } \\
\mathbf{2 0 0 0 - 2 0 1 0}\end{array}$ & $\begin{array}{c}\text { Mortalidade } \\
\text { (Nsc. vivos } \\
\text { - óbtos) }\end{array}$ & SM & TLM \% \\
\hline Caçador & 7.440 & 10.116 & -2.676 & $-3,78$ \\
\hline Calmon & -80 & 580 & -660 & $-19,49$ \\
\hline Lebon Régis & 156 & 1.700 & -1.544 & $-13,04$ \\
\hline Macieira & -74 & 120 & -194 & $-10,62$ \\
\hline Matos Costa & -365 & 358 & -723 & $-25,47$ \\
\hline Rio das Antas & 14 & 338 & -324 & $-5,27$ \\
\hline Timbó Grande & 666 & 1.139 & -473 & $-6,60$ \\
\hline TOTAL & $\mathbf{7 . 7 5 7}$ & $\mathbf{1 4 . 3 5 1}$ & $\mathbf{- 6 . 5 9 4}$ & $-\mathbf{6 , 3 4}$ \\
\hline
\end{tabular}

Fonte: Elaboração própria segundo os dados dos Censos Demográficos IBGE e Estatística Vitais - DATASUS/MS

Todavia esses municípios não foram capazes de absorver a maior parte da população que migrou. Isso revela então que os migrantes direcionaram-se, em sua grande maioria, para fora da microrregião, ou seja, em direção a outras regiões de Santa Catarina ou até mesmo para outros estados. Essa evasão populacional, como afirmam Mioto, Lins e Mattei (2010, p.304), "está ligada à falta de perspectiva dos habitantes, principalmente daqueles envolvidos com as pequenas propriedades agrícolas familiares".

Os fatores de expulsão ressaltados por Singer (1980) - novas formas capitalistas e transformações sociais - são predominantes nessa microrregião. Introdução de novas formas de trabalho, diminuição de ganhos na produtividade, dificuldade de manutenção das atividades na agricultura, mecanização da produção rural e pouca diversidade econômica na microrregião, dentre outros, tiveram importante papel na expulsão progressivamente da população local, principalmente do meio rural. 
MATTEI, L.F. \& HENRIQUES, F.L. O processo migratório em Santa ...

Isto é relevante porque o desenvolvimento do Vale do Rio do peixe está fortemente condicionado pelos movimentos que ocorrem na atividade agroindustrial, a qual continua sendo a principal atividade econômica da microrregião de Joaçaba, sendo responsável inclusive pela maior percentagem do produto interno bruto dos municípios que compõem essa região. Como historicamente essa microrregião se constituiu a partir de uma economia de pequenos produtores agrícolas familiares, a ascensão do sistema agroindustrial comandado pelas grandes empresas agroindustriais modernizadas impôs a esse segmento de produtores um conjunto de mudanças que acabaram repercutindo na própria distribuição populacional local e regional.

A relação entre o pequeno produtor rural e a agroindústria passou a ser dada através de um sistema de integração, onde a empresa oferece os insumos e o suporte técnico necessário, enquanto o pequeno produtor, integrado ao sistema, participa com a força de trabalho e as instalações necessárias - como, por exemplo, a construções e manutenção de aviários ou chiqueiros (MIOTO, LINS E MATTEI, 2010).

Tais produtores recebiam por produtividade, mas seus lucros passaram a ser menores dos que obtinham quando agricultura familiar. Criou-se o vínculo de subordinação, que com o tempo foi se agravando, visto que, as agroindústrias cobravam uma série de exigências que muitos não tinham condições de cumprir, além da restrição de acesso ao crédito para os produtores. Outro problema caracterizou-se no intenso trabalho necessário para garantir a qualidade e produtividade de suas criações (MIOTO, LINS E MATTEI, 2010).

Outro agravante para a microrregião é o fato de que há poucas opções de sustentação financeira, uma vez que a agroindústria é atividade que mais dá retorno financeiro para a maioria desses municípios. Também há poucas alternativas econômicas de investimento na região, resultando na falta de perspectivas dos indivíduos levando, consequentemente, a migração destes para áreas de atração populacional - que apresentam maior crescimento econômico. 
MATTEI, L.F. \& HENRIQUES, F.L. O processo migratório em Santa ...

Mais um ponto a ser destacado é a progressiva saída dos jovens das áreas rurais pela busca de melhores salários e qualificação profissional. Essa população que migra é a que está vinculada ao crescimento vegetativo, resultando em pontos negativos para a localidade devido à estagnação da população ou até mesmo a um crescimento diminutivo da mesma (MIOTO, LINS E MATTEI, 2010).

\section{Considerações finais}

A Migração está historicamente atrelada às mudanças decorrentes do desenvolvimento econômico, principalmente do sistema capitalista que, de acordo com Singer (1980), concentrou a riqueza e as atividades econômicas em alguns espaços geográficos específicos e gerou desigualdades sociais e regionais que se caracterizam como combustível para o processo migratório. Essa mobilidade espacial é entendida dentro de um contexto socioeconômico dinâmico que predomina nos movimentos em direção a locais com melhores índices de desenvolvimento humano, privilegiando os espaços urbanos (HARVEY, 2006).

Recordando que o debate entre as abordagens teóricas acerca do fenômeno migratório enfatizam a importância da força de atração ou expulsão que distingue cada região, bem como as características positivas ou negativas que levam as pessoas a migrar ou não, destacando-se neste caso vantagens econômicas, melhor infraestrutura, nível de desenvolvimento humano, ou clima, escassez de alimento, desemprego e até mesmo diferenças culturais.

Levando em consideração essa base teórica, interpretaram-se as características da mobilidade populacional dentro da microrregião de Joaçaba no período entre 2000 e 2010 a partir do processo de colonização, da análise da dinâmica socioeconômica atual e das mudanças no processo produtivo visando obter mais elementos que contribuem para explicar o movimento migratório em curso nesse espaço geográfico. 
MATTEI, L.F. \& HENRIQUES, F.L. O processo migratório em Santa ...

Essa microrregião, pertencente ao Meio-Oeste Catarinense e também chamada de Vale do Rio do Peixe, presenciou uma colonização e uma formação econômica em que o imigrante europeu desempenhou um papel decisivo. Eles estabeleceram pequenas atividades comerciais - caracterizadas pela exploração de madeira e erva mate e pequenas atividades agropecuárias (criação de animais com destaque para os suínos e aves), que, com o novo padrão de crescimento econômico, modernizou-se transformando o complexo agrícola-comercial no moderno sistema agroindustrial.

Com relação à economia das secretarias regionais localizadas na microrregião, os setores da indústria e de serviços participam com a maior parcela do PIB, com destaque para a indústria. No geral, essas secretarias apresentam situações econômicas semelhantes, sendo que apenas a secretaria de Caçador teve desempenho socioeconomicamente inferior às demais e saldos migratórios negativos.

Confirmando o fato do comportamento da mobilidade populacional estar ligada ao desempenho econômico, a Microrregião de Joaçaba pode ser caracterizada como uma microrregião pouco dinâmica, particularmente sendo um território com poucas atrações populacionais. Mesmo possuindo certo número de empregos em vários setores econômicos, as secretarias não comportam grande parte da população economicamente ativa e não oferecem grandes vantagens econômicas em outras áreas; além de apresentar um índice de urbanização alto e progressivo, principalmente entre os jovens. A consequência geral é que os saldos migratórios foram negativos, com um maior número de indivíduos saindo do que permanecendo na microrregião.

A falta de dinamismo da região e os problemas com os pequenos produtores rurais são os principais fatores que afetam negativamente essa região. Desde os anos de 1990, o setor primário enfrenta uma série de dificuldades associada às mudanças econômicas, como os avanços tecnológicos nas atividades agrícolas, a abertura comercial, a diminuição da renda dos 
MATTEI, L.F. \& HENRIQUES, F.L. O processo migratório em Santa ...

produtores e as próprias exigências das grandes agroindústrias que acabam eliminando os agricultores anteriormente integrados.

Outros setores econômicos que possibilitariam a diversificação das atividades e acrescentariam renda ao produtor rural poderiam contribuir para a manutenção das pessoas nas atividades rurais, bem como aumentar o número de empregos na área rural microrregional. Dentre essas atividades destacam-se o turismo rural, pecuária leiteira, industrialização rural, comercialização de outros produtos rurais, investimento em educação, etc. Isso tornaria a área rural mais atrativa $\mathrm{e}$ possibilitaria a permanência dos jovens nesse espaço geográfico, contribuindo para a continuidade dessa atividade produtiva, além da diversidade de produção, o que geraria uma nova dinâmica da economia local.

\section{Referências bibliográficas}

BENKO, George. Economia, espaço e globalização na aurora do século XXI. São Paulo: Hucitec, 1996.

BRASIL, Instituto Brasileiro de Geografia e Estatística (IBGE). Censo demográfico (2000). Disponível em: < http://www.ibge.gov.br/home/estatistica/populacao/default_censo_ 2000.shtm>. Acesso em: 5 out. 2011.

BRASIL, Instituto de Pesquisa Econômica Aplicada (IPEA). IPEAData. Disponível em: $<$ http://www.ipeadata.gov.br/Default.aspx $>$. Acesso em: 5 out. 2011.

BRASIL, Programa das Nações Unidas para o Desenvolvimento (PNUD). Ranking decrescente do IDH-M dos municípios do Brasil (2000). Disponível em: < http:www.pnud.org.br/atlas/ranking/IDHM\%2091\%2000\%20decrescente\%20\%28pelo\%20dados\%20de\%2 02000\%29.htm>. Acesso em: 15 out. 2010. 
MATTEI, L.F. \& HENRIQUES, F.L. O processo migratório em Santa ...

GOULARTI FILHO. A. Formação Econômica de Santa Catarina: uma tentativa de síntese. In MATTEI, L; LINS, H.N (Orgs.) A socioeconomia catarinense: cenários e perspectivas no início do século XXI. Chapecó: Argos, 2010.

GOULARTI FILHO, A. Formação econômica de Santa Catarina. Florianópolis: Cidade Futura, 2002.

HARVEY, D. Espaços de Esperança. São Paulo: Ed. Loyola, 2 edição, 2006 (tradução: Adail Ubirajara Sobral e Maria Stela Gonçalves).

LAGO, P.F. Santa Catarina: dimensões e perspectivas. Florianópolis: UFSC, 1978.

MATTEI, L; LINS, H.N. Tendências e desafios do desenvolvimento socioeconômico catarinense. In MATTEI, L; LINS, H.N (Orgs.) A socioeconomia catarinense: cenários e perspectivas no início do século XXI. Chapecó: Argos, 2010.

MIOTO, B. T. O movimento migratório em Santa Catarina no limiar do século XXI. 2008. 85 f. Trabalho de Conclusão de Curso (Bacharelado em Ciências Econômicas) - Universidade Federal de Santa Catarina, Florianópolis 2008.

PEIXOTO, J. As teorias explicativas das migrações: teorias micro e Macro-sociológicas. SOCIUS. Lisboa, 2004. $\rightarrow$ peguei da net mas tinha discrições, deixo assim?

RAVEnSteIN, E. G. As Leis da Migração. In MOURA, H.A (org.) Migração Interna: textos selecionados. BNB. Fortaleza, 1980 .

REGENSBURGER, J. Indústria e espaço urbano: Implicações sócio-espaciais no município de Joaçaba - SC. 2006. 163 f. 
MATTEI, L.F. \& HENRIQUES, F.L. O processo migratório em Santa ...

Dissertação (Pós-Graduação em Geografia) - Universidade Federal de Santa Catarina, Florianópolis, 2006.

SANTA CATARINA, Governo do Estado de Santa Catarina. Secretaria de Estado de Desenvolvimento Regional. Disponível em: $\quad<$ http://www.sc.gov.br/conteudo/governo/regionais/joacaba. htm>. Acesso em: 15 out. 2010.

SANTA CATARINA, Secretaria de Desenvolvimento Regional (SDR). Municípios de Abrangência. Disponível em: $<$ http://www.sc.gov.br/conteudo/governo/paginas/index_secretaria sregionais.htm>. Acesso em: 15 out. 2010.

SINGER, P. Migrações Internas: considerações teóricas sobre seu estudo. In MOURA, H.A (org.) Migração Interna: textos selecionados. Fortaleza: BNB, 1980.

THEIS, M.I. A dinâmica espacial recente da economia catarinense. In MATTEI, L; LINS, H.N (Orgs.) A socioeconomia catarinense: cenários e perspectivas no início do século XXI. Chapecó: Argos, 2010.

Recebido em março de 2013 Aceito em dezembro de 2013 